\title{
An investigation of the properties of conventional and severe shot peened low alloy steel
}

Pham Quang Trung*, David Lee Butler, Nay Win Khun

School of Mechanical and Aerospace Engineering, Nanyang Technological University, Singapore, 639798

\section{*Corresponding author:}

Pham Quang Trung, Metrology Laboratory, N3.1-B3b-03, Nanyang Technical

University, 50 Nanyang Avenue, Singapore 639798

Email: quangtru001@e.ntu.edu.sg

This work was presented on Shot peening section during 'The 30th International Conference on Surface Modification Technologies, 2016, Milan, Italy' (SMT30, ID 61, entitled 'Comparison of the effects of conventional shot peening and severe shot peening processes on the mechanical and tribological properties of shot peened AISI 4340') and was encouraged to submit a manuscript to the Materials Research Express journal after adding some nessesary information. 


\title{
An investigation of the properties of conventional and severe shot peened low alloy steel
}

\begin{abstract}
The effects of the conventional shot peening and severe shot peening process on the mechanical and tribological properties of shot peened AISI 4340 high strength steel were systematically investigated. Comparing with the conventional shot peened sample, the ultrafine grain surface layer with a depth of about $20 \mu \mathrm{m}$ generated by the severe shot peening process can enhance the hardness and wear resistance of the treated material. However, deeper dimples generated by the high media velocity in the severe shot peening process resulted in a higher surface roughness, which is considered as a side effect of this method reducing the fatigue life of the material. Applying a smaller shot size with an appropriate intensity can be used to peen the severe shot peened samples to not only reduce the surface roughness and friction coefficient but also improve the wear resistance for these samples.
\end{abstract}

\section{Keywords}

Severe shot peening, friction, microstructure, hardness, shot peening, wear

\section{Introduction}

Shot peening is a cold working method, which has been widely used in industries ranging from aerospace to construction due to the compressive residual stresses induced in the material by the process, which can prevent the formation of surface cracks and enhance the fatigue life of the mechanical part's sub-surface. ${ }^{1,2}$ In the shot peening process, the shot peening media impact on the surface of metal components causing plastic deformation and subsequently inducing compressive stresses in the sub-surface. The surface area of the shot peened material become harder and rougher than its surrounding unaffected surface area. ${ }^{1}$

Recently, ultrafine grain materials, especially nanostructured materials have attracted significant interest from both industry and science. They are expected to 
deliver superior mechanical properties when compared with the normal grain size specimens. ${ }^{3,4}$ From the literature, ${ }^{5}$ surface properties have an important influence on failures of engineering parts, for example in fatigue fracture, fretting fatigue, wear and corrosion, etc. In many applications, it is recommended that it is not necessary to make entire components by ultrafine grain materials. Thus, the material with ultrafine grain on the surface is supposed to highlyimprove the surface properties of thespecimenwithout changing its chemical components and shapes. 3,5 To create an ultrafine grain material, an aggressive form of shot peening is required with much higher intensity and coverage. This process is known as severe shot peening (SSP) and has been successfully used to generate the ultrafine grain layer on a yariety of materials, including pure materials, alloys, and intermetallic compounds. ${ }^{5}$ The majority of experiments reported in the literature considered the effects of ultrafine grain layers on the improvement in mechanical material behavior. It also worth to note that the high intensity, in the case of severe shot peening process is effective to induce a high magnitude of compressive stress as well as generate the ultrafine grain layer on the surface of peened material. However, the surface roughness of the severe shot peened target material is relatively high, which is considered as a side effect of this process. To improve the surface finish of the severe shot peened component, a second shot peening process with a smaller shot size media and a reasonable intensity should be employed. This process is called as re-severe shot peening.

It was reported by Singh et al. ${ }^{6}$ that wear volume loss of quenched and tempered SAE 6150 steel could be reduced by employing the shot peening process. Mitrovic et al. ${ }^{7}$ proved that both shot peened $36 \mathrm{CrNiMo} 4$ and $36 \mathrm{NiCrMo} 16$ alloy steel showed an improved wear resistance under dry and lubricated contact condition tests. Kuruschov ${ }^{8}$ and Richardson ${ }^{9}$ reported that there was little increase in hardness caused by work 
hardening on the wear resistance. Matsui et al. ${ }^{10}$ investigated the tribological performance of steel under the dry rolling/sliding contact conditions and found that the samples with pre-shot peening treatment exhibited an improved wear resistance. The wear performance of AISI 1017 steel after severe shot peening was studied by Unal et al.. ${ }^{11}$ The results suggested that the hardness and stiffness of the sample surface enhancedas the high shot peening intensity and wear durability improved as a result.

However, the data on tribological properties of shot peened, severe shot peened and re-severe shot peened steel are not easily available. Among steels, AISI 4340, high strength steel, is known for its toughness and its ability to attain high strength in the heat-treated condition. It is a widely used for steel crankshafts, automotive, forged hydraulic and machine tool applications.

In this paper, AISI 4340 high strength steel samples were shot peened under conventional and severe conditions to investigate their mechanical and tribological properties. The hardness distribution against the depth from the surface of the shot peened components was evaluatedemploying a nanoindentor and their frictional and wear properties were studied using a ball-on-disc micro-tribological experiment.

\section{Materials and methods}

In this study, AISI 4340 steel was used as the material for all experiments. The nominal chemical composition of the AISI 4340 low alloy steel (weight \%) is composed of C ( 0.34), Si $(\sim 0.24), \operatorname{Mn}(\neg 0.51), \operatorname{Cr}(\sim 0.91) \mathrm{Ni}(\sim 1.54)$ and Mo $(\sim 0.25)$. The steel was heat treated at $815^{\circ} \mathrm{C}$, quenching in oil at $\sim 20^{\circ} \mathrm{C}$, and followed by tempering at the temperature of $230^{\circ} \mathrm{C}$ for 2 hours.

The samples were then mounted on the fixture and peened under different conditions. Table 1 presents the applied shot peening parameters for the experiments. 
To achieve a required coverage of $120 \%$, the specimen was peened in 150 seconds. Therefore, the peening time to obtain the coverage of $1200 \%$ is 1500 seconds. Air blast shot peening machine (Abrasive Engineering Pte. Ltd.) was employed to perform the experiment. The media used in this research were S230, and S110, the round high quality steel shot, which are the common media used in industry.

\section{Results and discussion}

Prior to investigate the microstructure, the shot peened samples were cross-sectioned in the transverse direction, polished and etched with etchant solution (4\% picral and $2 \%$ nital were mixed together in equal parts). The details of the a chemical - mechanical polishing process are displayed in table 2 . The microstructures of the cross-sectional shot peened samples were characterized by anoptical microscope (Zeiss Axioskop 2, JVC color video camera) and scanning electron microscopy (SEM, JEOL-JSM5600LV).

Figure 1 presents the shape of media S230 and S110 which were used to treat the samples. The image shows that the media is spherical with mean diameter of S230 and S110 of about 600 and $300 \mu \mathrm{m}$, respectively. The mean mass of each shot S230 and $\mathrm{S} 110$ are $8.8 \pm 0.5 \times 10^{-4} \mathrm{~g}$ and $1.1 \pm 0.1 \times 10^{-4} \mathrm{~g}$ respectively and the mean hardness of S230 and S110 are about $500 \pm 30 \mathrm{Hv}$.

Figure $2 a$ and $b$ show the cross-sectional microstructure of the as-received steel sample observed at different magnifications. It can be clearly seen that the first layer with the depth of about $20 \mu \mathrm{m}$ of the as-received sample is iron oxide layer attributed to heat treatment process. This iron oxide layer results in poor mechanical properties which are not useful in mechanical applications. Therefore, the formation of this iron oxide layer in important mechanical parts is prevented by using vacuum furnace during 
heat treatment process or by conducting a polishing process after heat treatment. The normal grain size of the as-received sample has a mean diameter of about $10 \mu \mathrm{m}$. Figure $2 c$ and $d$ present the cross-sectional microstructure of conventionally shot peened sample 2 (CSP2) observed at different magnifications. The iron oxide layer is partly removed from the surface of the peened sample (Fig. $2 c$ ). The iron oxide layer with the depth of about 3-5 $\mu \mathrm{m}$ is still available on the top surface of conventional shot peened sample (Fig. 2c). Under the plastic deformation formed by the shot peening process, the grain size of the second layer is reduced to about $5 \mu \mathrm{m}$. This layer has a depth of $100-$ $150 \mu \mathrm{m}$ from the surface (Fig. $2 d$ ). The result demonstrates that shot peening is a good process to remove the iron oxide layer from the surface. Figure $2 e$ and $f$ show the crosssectional microstructure of severe shot peened (SSP) sample observed at different magnifications. It can be clearly seen that the iron oxide layer is totally removed by the high energy of shots in the severe plastic deformation condition (Fig. $2 e$ and $f$ ). There are three different grain size layers formed on the cross-sectional microstructure of the severe shot peened sample. The first layer with the ultrafine grain size, which cannot be discerned by the normal optical microstructure equipment, appears on the top surface of the shot peened steel sample. The depth of zone is about $20 \mu \mathrm{m}$, which is generated by receiving very high strain from the shot caused by severe plastic deformation. The next layer with asmall grain size of approximately $2 \mu \mathrm{m}$ has the depth of $150 \mu \mathrm{m}$. This layer also underwent the high strain process. Therefore, the grain size of this layer reduced smaller from the original grain size. The last layer is original grain size with the mean of grain size of about $10 \mu \mathrm{m}$, where the effect of deformation caused by shots is reduced significantly.

The hardness tests were performed using an Agilent G200 Nanoindenter equipment, with a depth limit of $2000 \mathrm{~nm}$. Figure $3 a$ exhibits the microhardness 
distribution along the depth from the surface of samples. During the heat treatment process in the normal furnace, carbon is lost on the surface and near-surface layers of the material. The depth of the layer which the carbon element escaped is about 300-500 $\mu \mathrm{m}$, and the quantity of amount of escaped carbon reduces from the surface into inside material. This phenomenon caused a reduction in the hardness of heated sample at the surface and near-surface layer (up to $500 \mu \mathrm{m}$ ).

The shot peening process induced the plastic deformation on the surface of the target causing work hardening on these peened samples. It is also clearly seen that comparing with the as-received specimen, the near-surface hardness of SSP, Re-SSP, CSP1, CSP2 sample have increased. The hardness of the surface layer of Re-SSP, SSP, CSP1, CSP2, as-received samples is $6.5,6.0,4.8,3.7$ and $3.1 \mathrm{GPa}$, respectively. The difference in hardness profile between severe and conventional shot peening condition occurs in about $50 \mu \mathrm{m}$ from the surface, where the ultrafine grain is formed in severe shot peened sample due to the high deformation process.

The surface roughness of the samples was measured by using a surface profilometer (Taylor Hobson Talyscan 150). In Fig. 3b, the measured arithmetic average (Sa), root mean squared $(\mathrm{Sq})$ surface roughness, themaximum height of surface (St) and theaverage distance between the five highest peaks and five lowest valleys ( $\mathrm{Sz}$ ) values of the treated AISI 4340 samplesare remarkably larger than those of the asreceived sample. The difference between treated samples and as-received sample are more clearly in thecase of St and $\mathrm{Sz}$ values because these values are sensitive to the high of peaks and the depth of dimples caused by the shot. It also can be clearly seen that using a smaller shot after severe shot peening process can reduce the surface roughness in all the $\mathrm{Sa}, \mathrm{Sq}, \mathrm{St}$ and $\mathrm{Sz}$ values. 
Figure $4 a-d$ shows the surface morphology and topographyof shot peened samples and Fig. $4 e$ presents surface morphology and topographyof the as-received sample. In Fig. $4 e$, the as-received sample has a relatively rough surface due to the formation of the iron oxide layer (caused by heat treatment process). Obvious dimples caused by the treatment appeared on the surface topographies of the peened sample as presented in Fig. $4 a-d$. The dimples become deeper and the surfaces become rougher in thecase of higher shot peening pressure. ${ }^{12}$ It is also clearly seen that the re-severe shot peening process can make the surface topography smoother by reducing the height of peak after severe shot peening. This result agrees with the measured surfaces roughness of the treated samples in Fig. $3 b$.

The tribological properties of shot peened samples were investigated by the ballon-disc micro-tribometer (CSM) machine. It is versatile equipment designed to measure the wear and the friction characteristics. The sliding friction coefficient was measured by the ratio of the friction force to the normal load on the pin. In this research, the pin stylus was kept stationary while the samples were mounted on the rotating disk. The tribological properties of the samples were studied by sliding against $100 \mathrm{Cr} 6$ steel balls (diameter of $6 \mathrm{~mm}$ ) in a circular path (radius of $1.5 \mathrm{~mm}$ ) during 40000 laps with a sliding speed of $50 \mathrm{~mm} / \mathrm{s}$ under a normal load of $5 \mathrm{~N}$ at room temperature (RT $\sim 22-$ $24^{\circ} \mathrm{C}$ ). During the sliding test, wear tracks were steadily made on the surface of the samples mounted on the rotating disc and the surface of the top of the ball mounted on the stationary pin due to the materials loss from friction/wear. The material removal can be associated with abrasive wear attributed to both two body and three body mechanisms. The average friction coefficient of each sample was obtained from three wear tests. Then, the width and the depth of wear tracks with surface profilometry were used to calculate the average wear volume loss of each specimen. Figure $5 a$ presents the 
friction coefficient between the shot peened samples against the $100 \mathrm{Cr} 6$ steel balls in the dry sliding wear tests. The results indicate that compared with the as-received sample, the friction coefficient in the cases of conventional shot peened samples (CSP1, CSP2) slightly increases, while the values of SSP and Re-SSP samples are noticeably higher. The friction coefficients between the steel samples, i.e. SSP, Re-SSP, CSP1, CSP2, and as-received against the $100 \mathrm{Cr} 6$ steel balls are $0.53,0.51,0.47,0.48$ and 0.46 , respectively. The possible reason is that the surface roughness plays a very important role to raise a higher friction by mechanical interlocking between two rubbing surfaces. ${ }^{13,14}$ The results can show that the samples with higher surface roughness (Fig. $3 \mathrm{~b}$ and Fig. 4) exhibit a higher friction coefficient for all the tests. However, in thecase of Re-SSP, the surface roughness values of Re-SSP sample is equal to that of CSP1 and smaller than that of CSP2 but the friction coefficient is still higher. As mentioned above, the ultrafine grain layers are formed on the surface and near-surface of the SSP sample and Re-SSP samples. This ultrafine grain layer has different properties compared with the original grain size of thematerial. ${ }^{5}$ Therefore, the higher friction coefficients in cases of Re-SSP come from the effect of this ultrafine grain layer. Figure $5 b$ shows the friction coefficients of the shot peened steels against the steel ball under the load of $5 \mathrm{~N}$ as a function of the number of laps. The friction coefficient increasing gradually in the first 10,000 laps(also called running-in period), that reason is due to the increased wear of asperities rubbing surfaces. ${ }^{12,}{ }^{15-19}$ From 10,000 laps onwards, the tested samples exhibit a steady friction coefficient during the entire sliding test, resulting from their stable wear. ${ }^{12,15-18}$

Figure 6 illustrates the wear volume of the shot peened steel AISI 4340 samples at different peened conditions tested against the steel ball under a normal load of $5 \mathrm{~N}$. Wear volumes were calculated from the wear track profile including width and the 
depth. The wear track profile was measured after tested friction coefficient for 40000 laps by using a surface profilometer (Taylor Hobson Talyscan 150). It is clear that the decreasing of wear volume in the tested samples are probably due to the increasing of the wear resistance associated with their risen surface hardness. ${ }^{12,19,20}$ It is further confirmed by considering the hardness distribution at the surfaces of these samples (Fig. 3a). The highest hardness surface sample (Re-SSP) has the lowest wear volume of $8 \times 10^{-3} \mathrm{~mm}^{3}$ and the lowest hardness surface sample (as-received) has the largest wear volume of $27 \times 10^{-3} \mathrm{~mm}^{3}$.

Figure 7 shows the wear track morphologyand topography of the shot peened AISI 4340 steel. Abrasive wear formed by the repeated sliding of the steel ball clearly creates grooves on the wear tracks under the load of $5 \mathrm{~N}$. The as-received sample has the largest wear track on the surface and consequently the highest material loss..$^{12,21-23}$ The severe shot peened and re-severe shot peened samples have smaller wear tracks and wear volumes compared to the conventional shot peened samples. This is due to the higher wear resistance of the shot peened samples can reduce their wear tracks. ${ }^{17,21-23}$ Figure $7 a-b$ also reveal that some dimples formed by impacts of the media during shot peening have a higher depth than that of the material removed by the sliding ball and thus can still be seen.

\section{Conclusion}

In this research, the low alloy steel AISI 4340 after quenching and tempering was shot peened under conventional and severe conditions to investigate their mechanical and tribological properties. After heat treatment, there was an iron oxide layer with a depth of about $20 \mu \mathrm{m}$ formed on the sample surface. This layer had poor mechanical properties and reduces the surface quality of mechanical parts. The conventional shot 
peening process could partly remove this layer and improve the properties of material while severe shot peening process totally removed it from the surface.

The severe shot peening generated an ultrafine grain layer with a depth of 20 $\mu \mathrm{m}$. The severe shot peening process increased the hardness of the surface and nearsurface of material as a result of promoted cold work hardening effect. The increasing surface hardness by applying conventional shot peening and severe shot peening process could improve the wear resistance properties of material, as a result of decreasing the wear volume of peened samples.

Severe shot peening process caused a high surface roughness on the surface of the sample due to the formation of deep indentations on the surface. Therefore, the risen surface roughness of the severetreated sample was responsible for their risen friction coefficient against the steel ball under the load of $5 \mathrm{~N}$. The high surface roughness was considered as a side effect of severe shot peening process. To reduce its side effect, additional shot peening process with smaller media was employed. This method not only reduced the surface roughness on severe shot peened surface samples but also improved the wear resistance of the low alloy steel (Re-SSP).

It could be concluded that the severe shot peening process could remove the iron oxide layer and generated an ultrafine grain layer on the surface of a low alloy steel; the experimental results showed that this layer had an influence on the mechanical and tribological properties of the treated AISI 4340 low alloy steel specimens.

\section{Acknowledgements}

The authors wish to/gratefully acknowledge Abrasive Engineering Pte Ltd for experimental investigations. This work was supported by the Nanyang Technological University (NTU) of Singapore. 


\section{References}

1. Baiker S. Shot peening: a dynamic application and its future, fourth ed.: Metal finishing news, 2014.

2. Kaysser W. Surface modifications in aerospace applications. Surface Engineering. 2001; 17: 305-12.

3. $\mathrm{Lu} \mathrm{K}$ and $\mathrm{Lu}$ J. Nanostructured surface layer on metallic materials induced by surface mechanical attrition treatment. Materials Science and Engineering: A. 2004; 375-377: 38-45.

4. Valiev R. Nanostructuring of metals by severe plastic deformation for advanced properties. Nat Mater. 2004; 3: 511-6.

5. Bagheri $\mathrm{S}$ and Guagliano $\mathrm{M}$. Review of shot peening processes to obtain nanocrystalline surfaces in metal alloys. Surface Engineering. 2009;25: 3-14.

6. Singh D and Mondal DP. Effect of quenching and tempering processes and shot peening intensity on wear behaviour of SAE-6150/steel. Indian Journal of Engineering and Materials Sciences. 2014; 21: 168-78.

7. Mitrovic S, Adamovic D, Zivic F, Dzunic D and Pantic M. Friction and wear behavior of shot peened surfaces of 36CrNiMo4 and 36NiCrMo16 alloyed steels under dry and lubricated contact conditions. Applied Surface Science. 2014; 290: 223-32.

8. Khruschov MM. Principles of abrasiye wear. Wear. 1974; 28: 69-88.

9. Richardson RCD. The wear of metals by hard abrasives. Wear. 1967; 10: 291309.

10. Matsui M and Kakishima H. Improvement of tribological performance of steel by solid lubricant shot-peening in dry rolling/sliding contact wear tests. Wear. 2006; 260: 669-73.

11. Unal O, Varol R, Erdogan A and Gok MS. Wear behaviour of low carbon steel after severe shot peening. Materials Research Innovations. 2013; 17: 519-23.

12. Khun NW, Trung PQ and Butler DL. Mechanical and tribological properties of shot peened SAE 1070 steel. Tribology Transactions. 2016; 59; 932-43. 
13. Barrett TS, Stachowiak GW and Batchelor AW. Effect of roughness and sliding speed on the wear and friction of ultra-high molecular weight polyethylene. Wear. 1992; 153: 331-50.

14. Svahn F, Kassman-Rudolphi $\AA$ and Wallén E. The influence of surface roughness on friction and wear of machine element coatings. Wear. 2003; 254: 1092-8.

15. Khun NW, Frankel GS and Sumption M. Effects of Normal Load, Sliding Speed, and Surface Roughness on Tribological Properties of Niobium under Dry and Wet Conditions. Tribology Transactions. 2014; 57: 944-54.

16. Khun NW, Loong PY, Liu E and Li L. Enhancing electrical and tribological properties of poly(methyl methacrylate) matrix nanocomposite films by coincorporation of multiwalled carbon nanotubes and silicon dioxide microparticles. Journal of Polymer Engineering. 2016; 36: 23-30.

17. Khun NW, Sun DW, Huang MX, Yang JL and Yue CY. Wear resistant epoxy composites with diisocyanate-based self-healing functionality. Wear. 2014; 313: 19-28.

18. Khun NW, Tan AWY, Bi KJW and Liu E. Effects of working gas on wear and corrosion resistances of cold sprayed Ti-6Al-4V coatings. Surface and Coatings Technology. 2016; 302: 1-12.

19. Trung PQ, Khun NW and Butler DL. Effects of shot peening pressure, media type and double shot peening on the microstructure, mechanical and tribological properties of low-alloy steel. Surface Topography: Metrology and Properties. 2016; 4: 045001 .

20. Schmidt I. Sliding wear of shot-peened austenitic manganese steels. Journal of Materials Science Letters. 1986; 5: 475-7. 


\section{List of table}

Table 1. Shot peening parameter conditions.

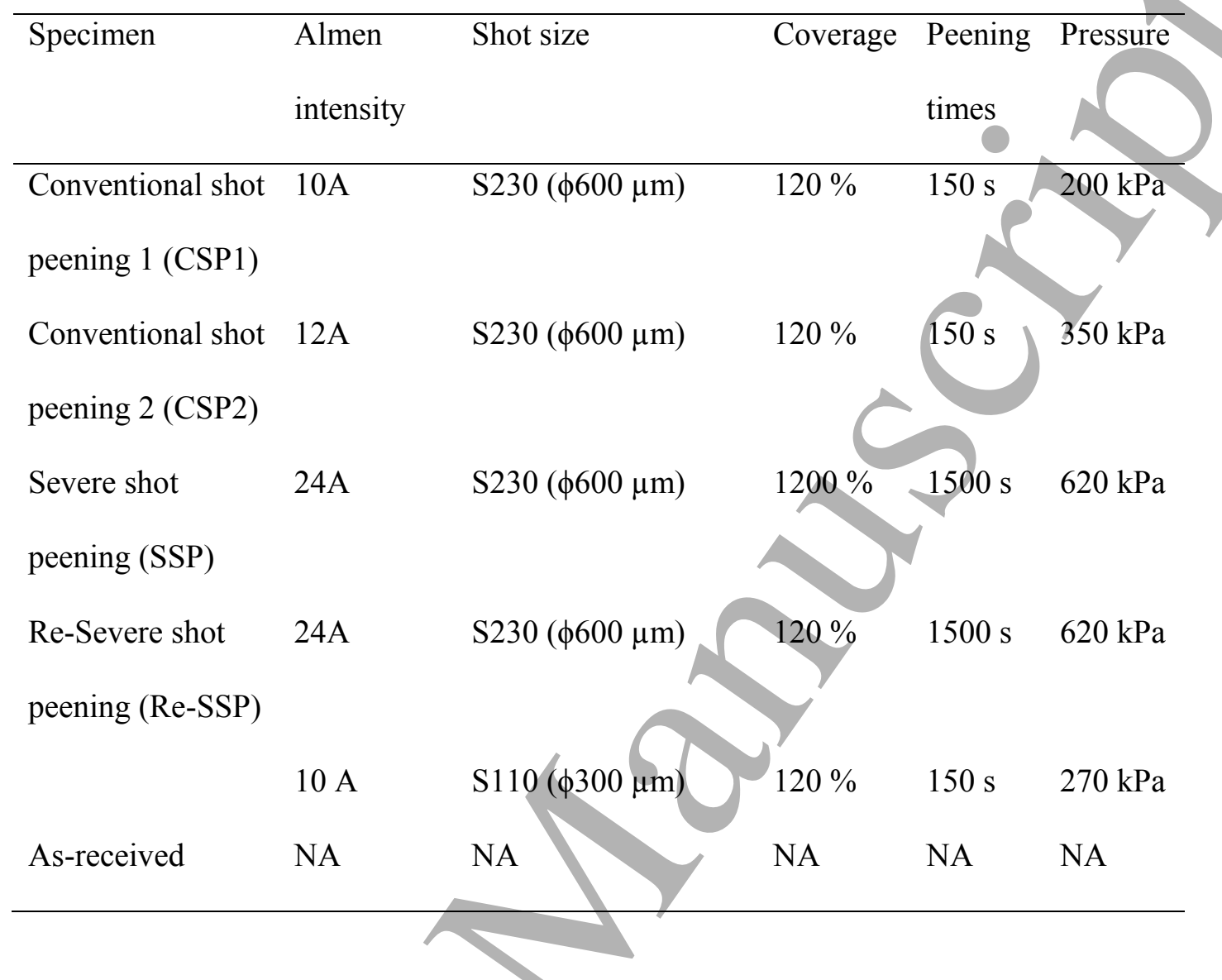


Table 2. Sample preparation parameters for microstructural observation.

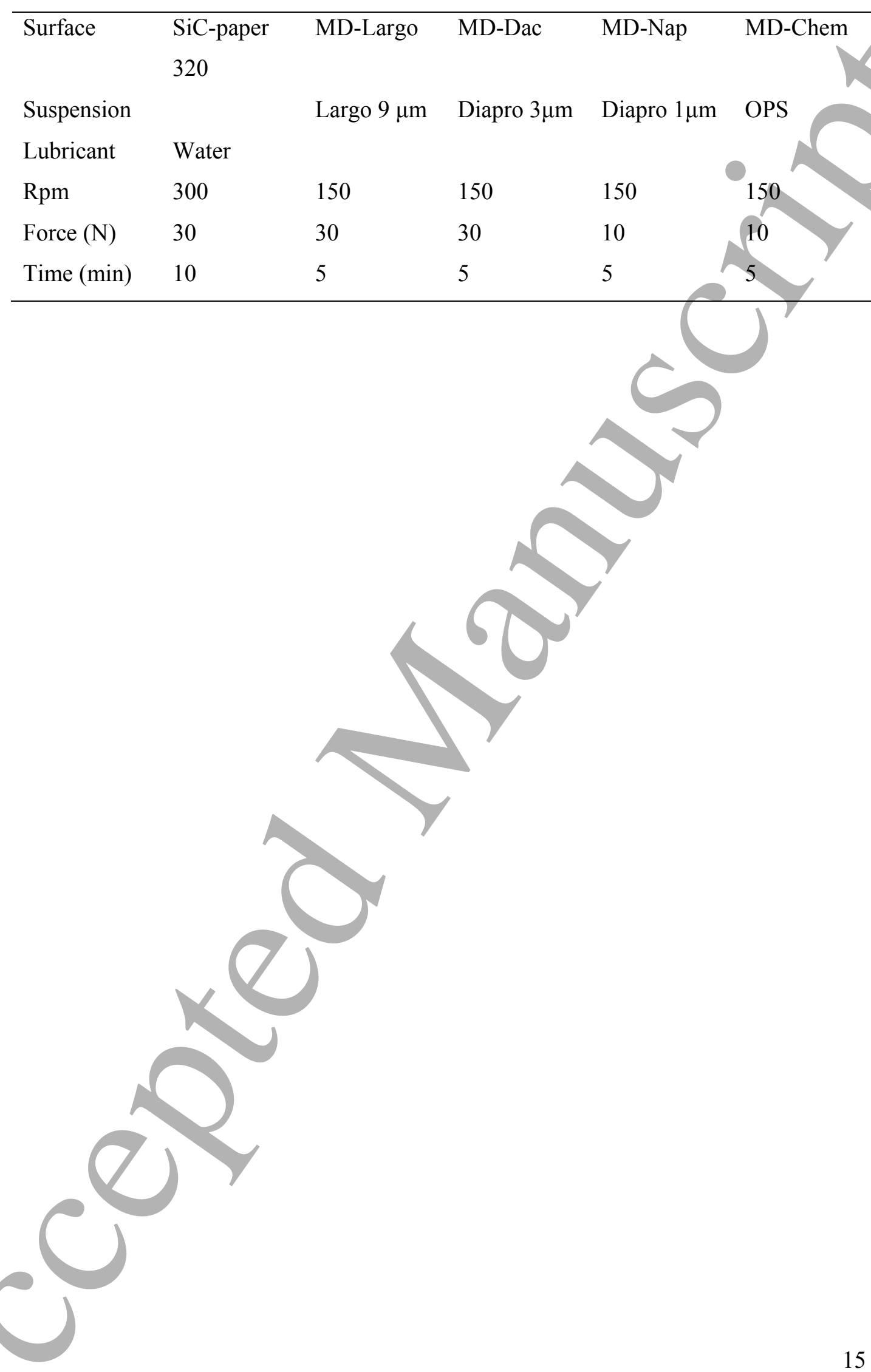


List of figures

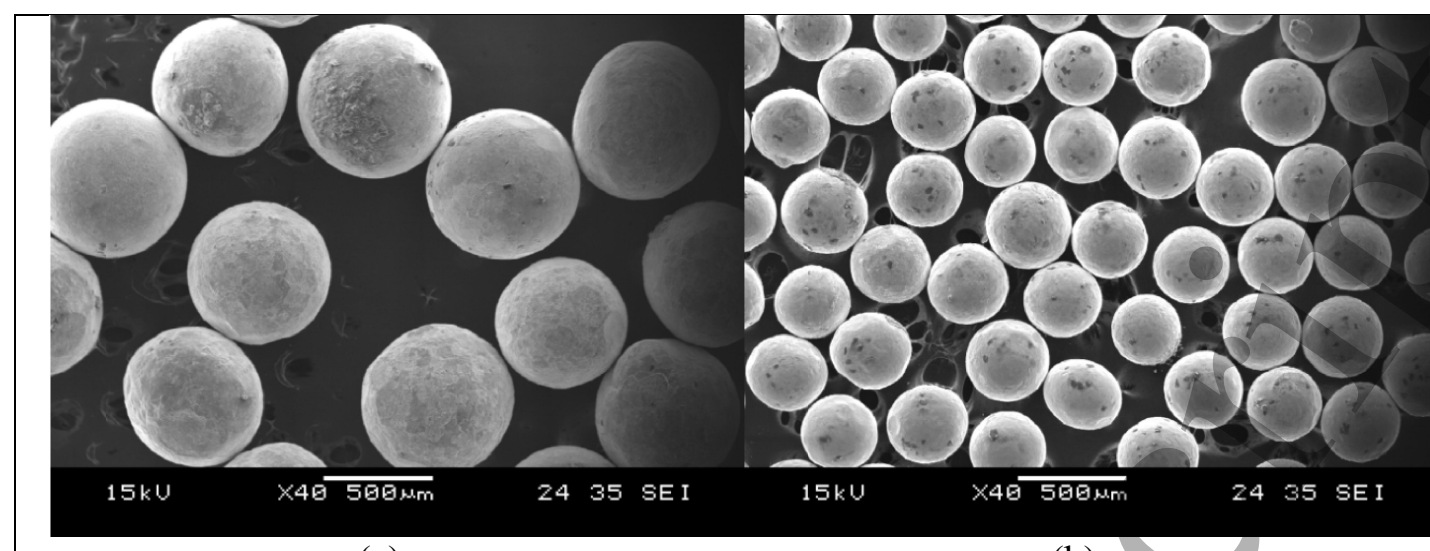

(a)

(b)

Figure 1. SEM micrograph of the media: (a) S230 and (b) S110. 


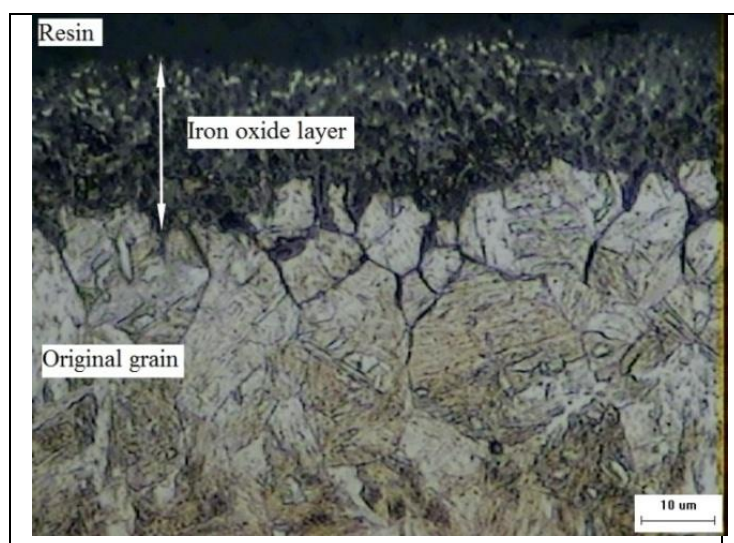

(a)

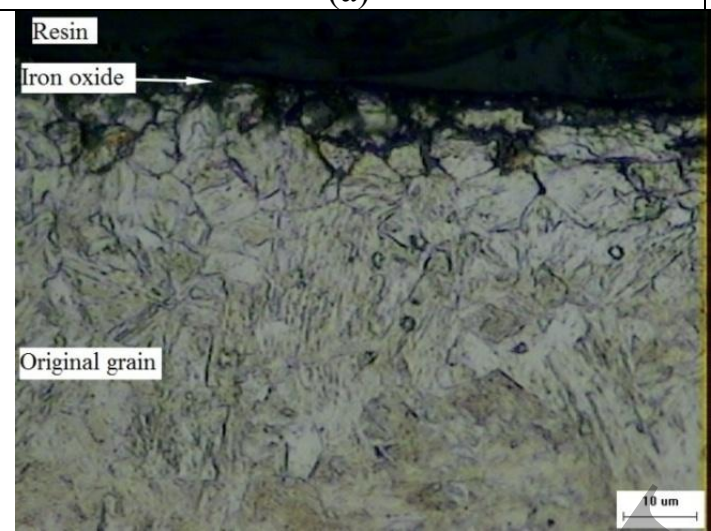

(c)

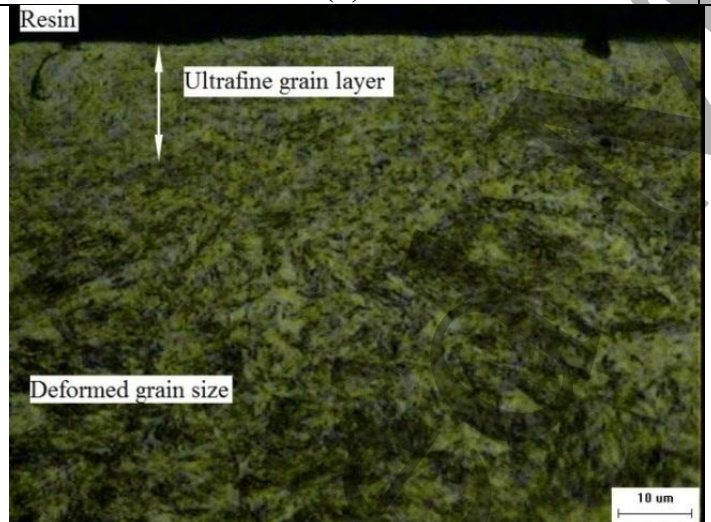

(e)

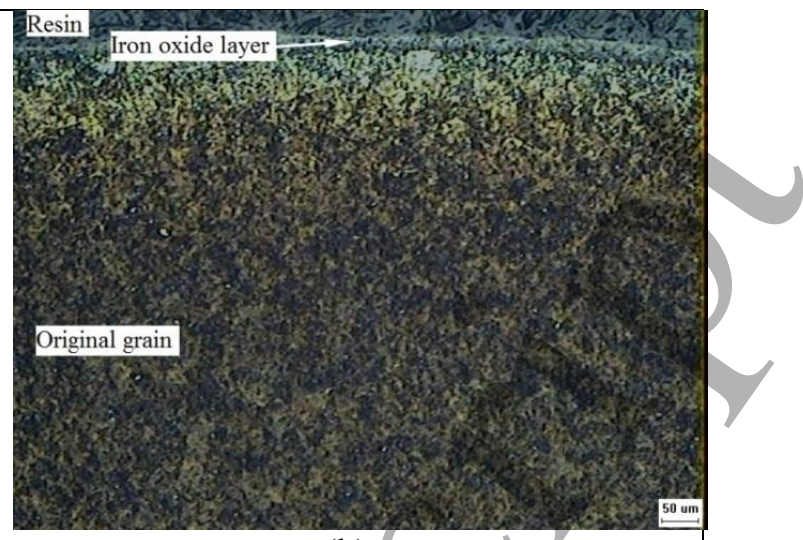

(b)

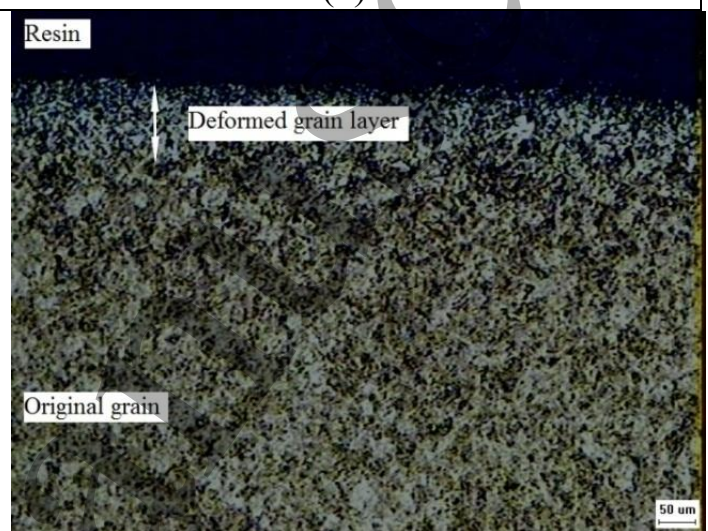

(d)

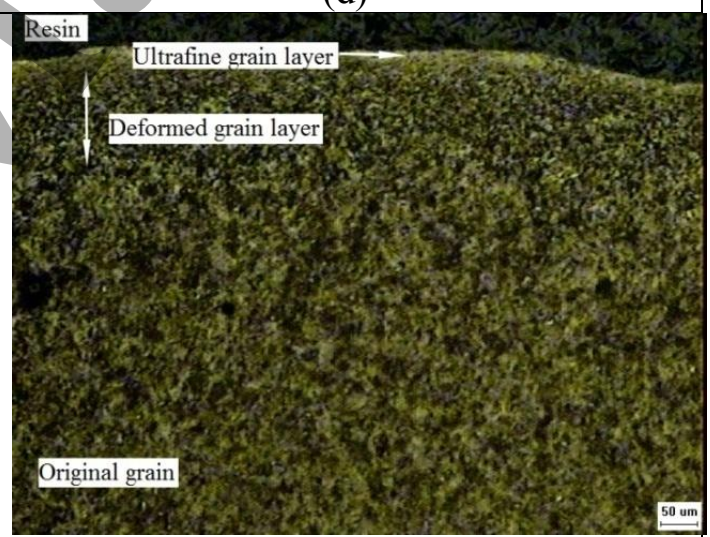

(f)

Figure 2. Cross-sectional microstructure of shot peened AISI 4340 steel at different magnifications: (a) and (b) as-received, (c) and (d) CSP2 sample, (e) and (f) SSP sample. 


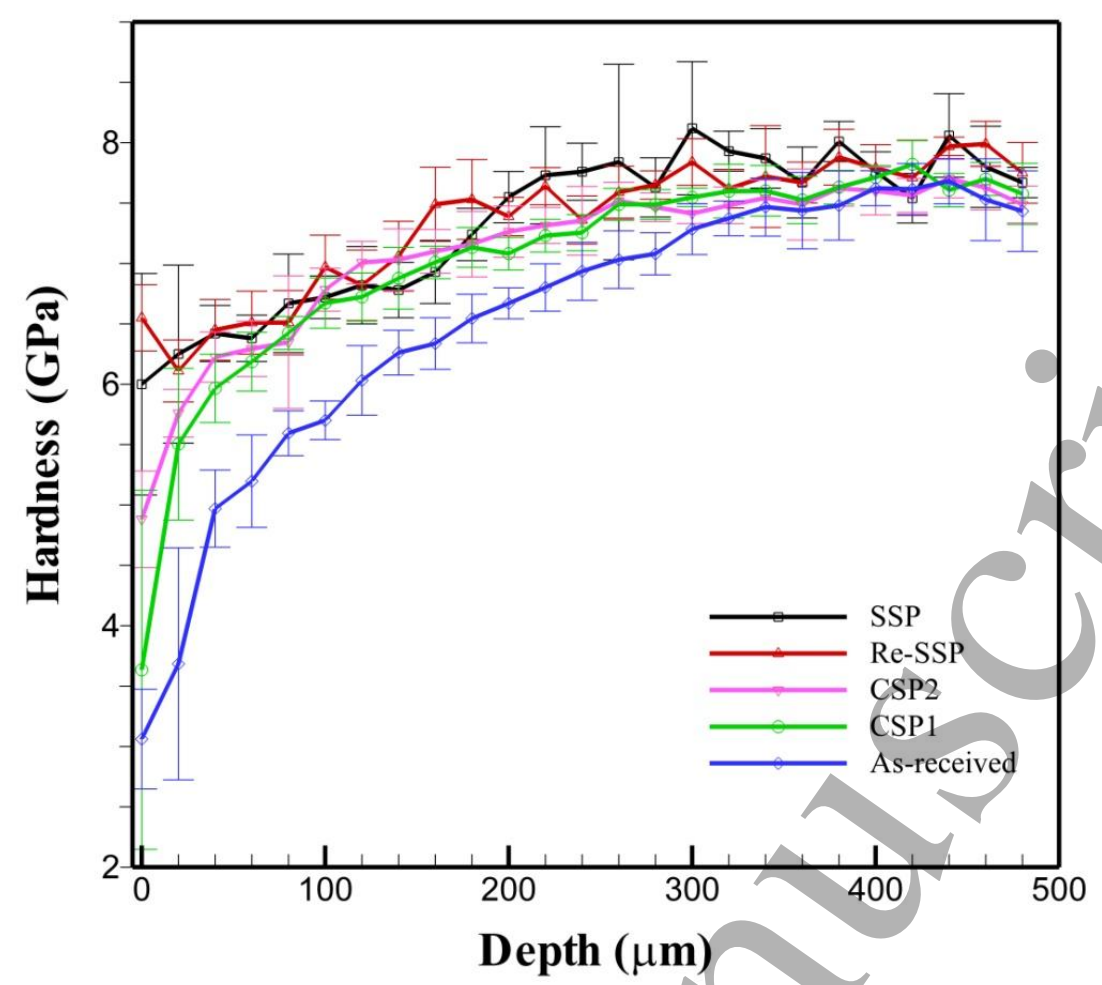

(a)

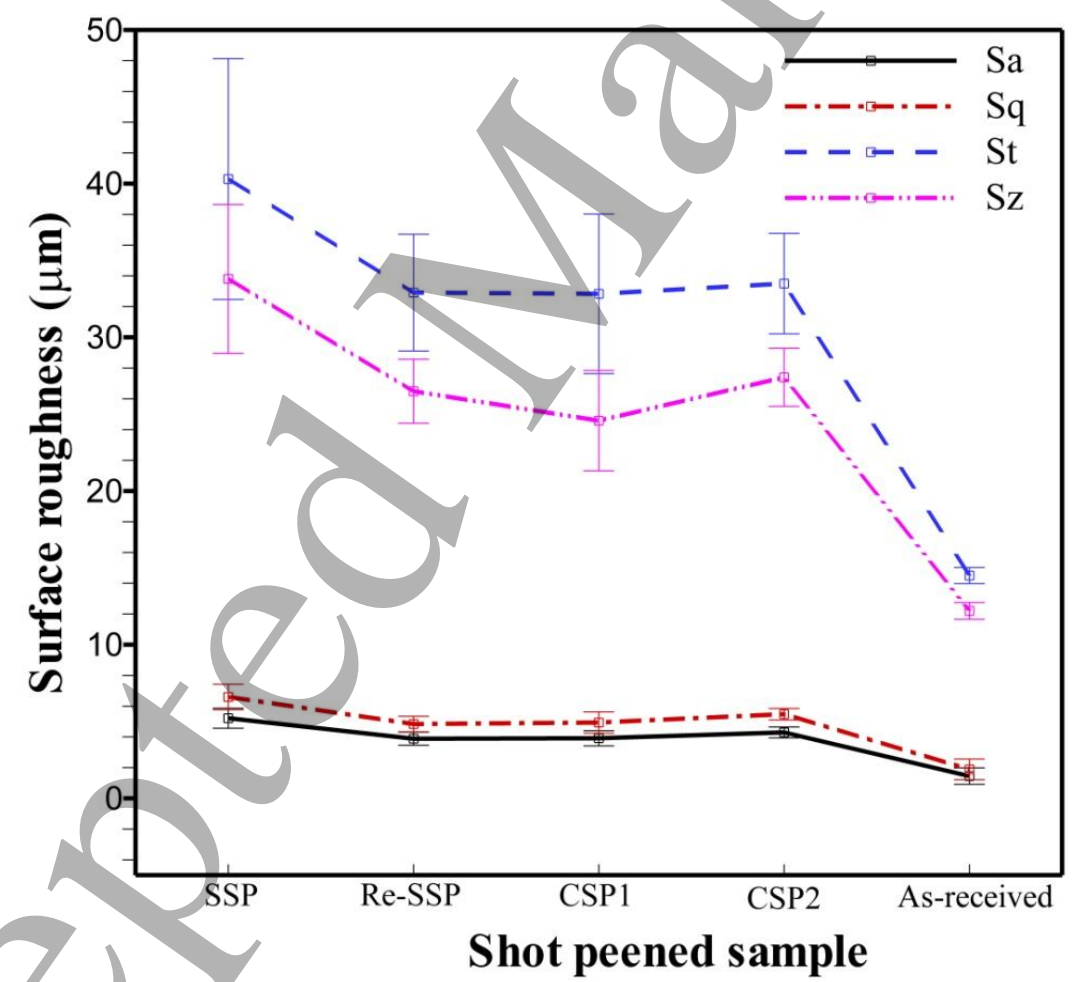

(b)

Figure 3. (a) Microhardness distribution along the depth from the surface of thesample and (b) Surface roughness of AISI 4340 steel after undergoing different shot peening conditions. 

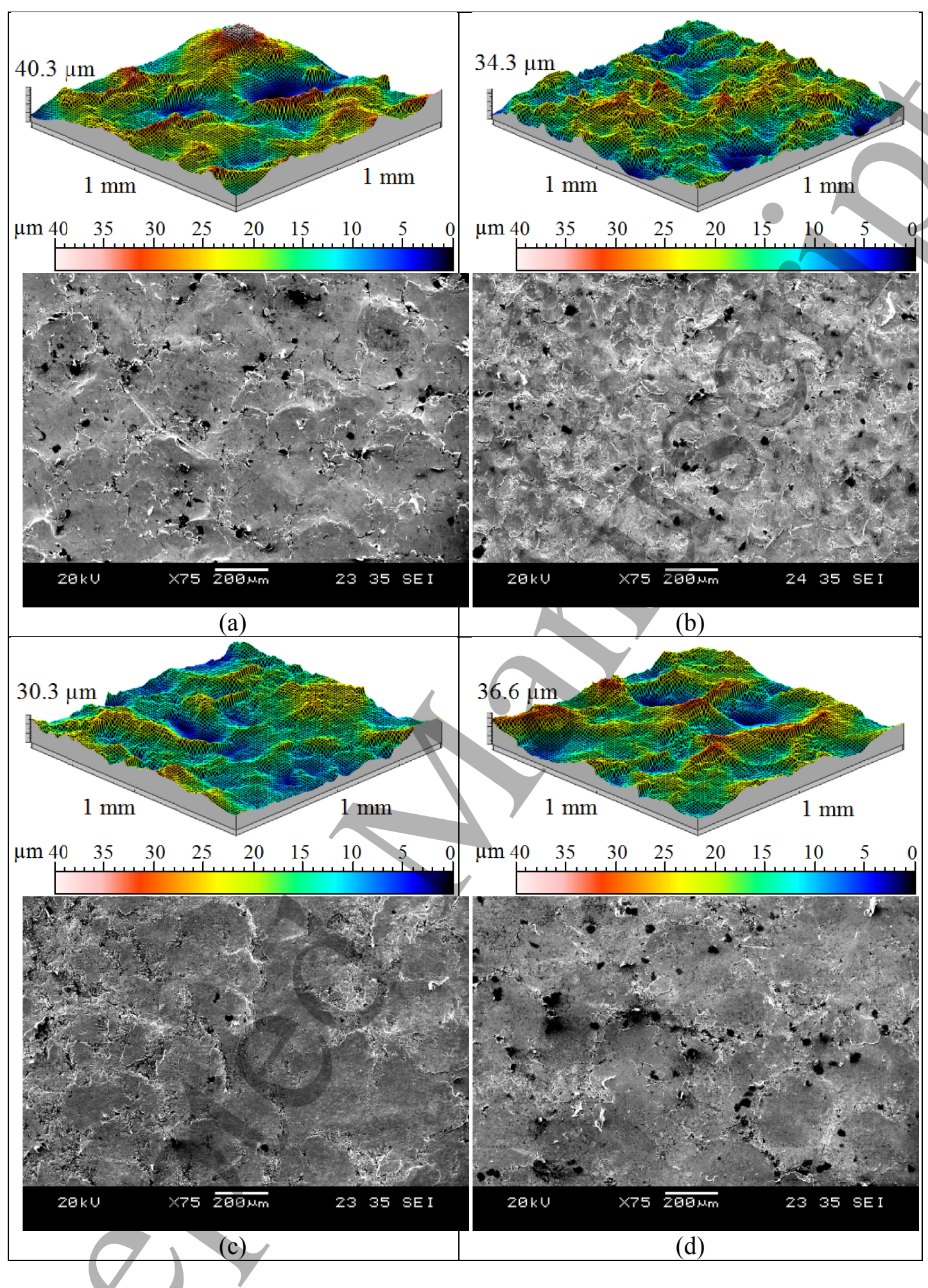

(d) 


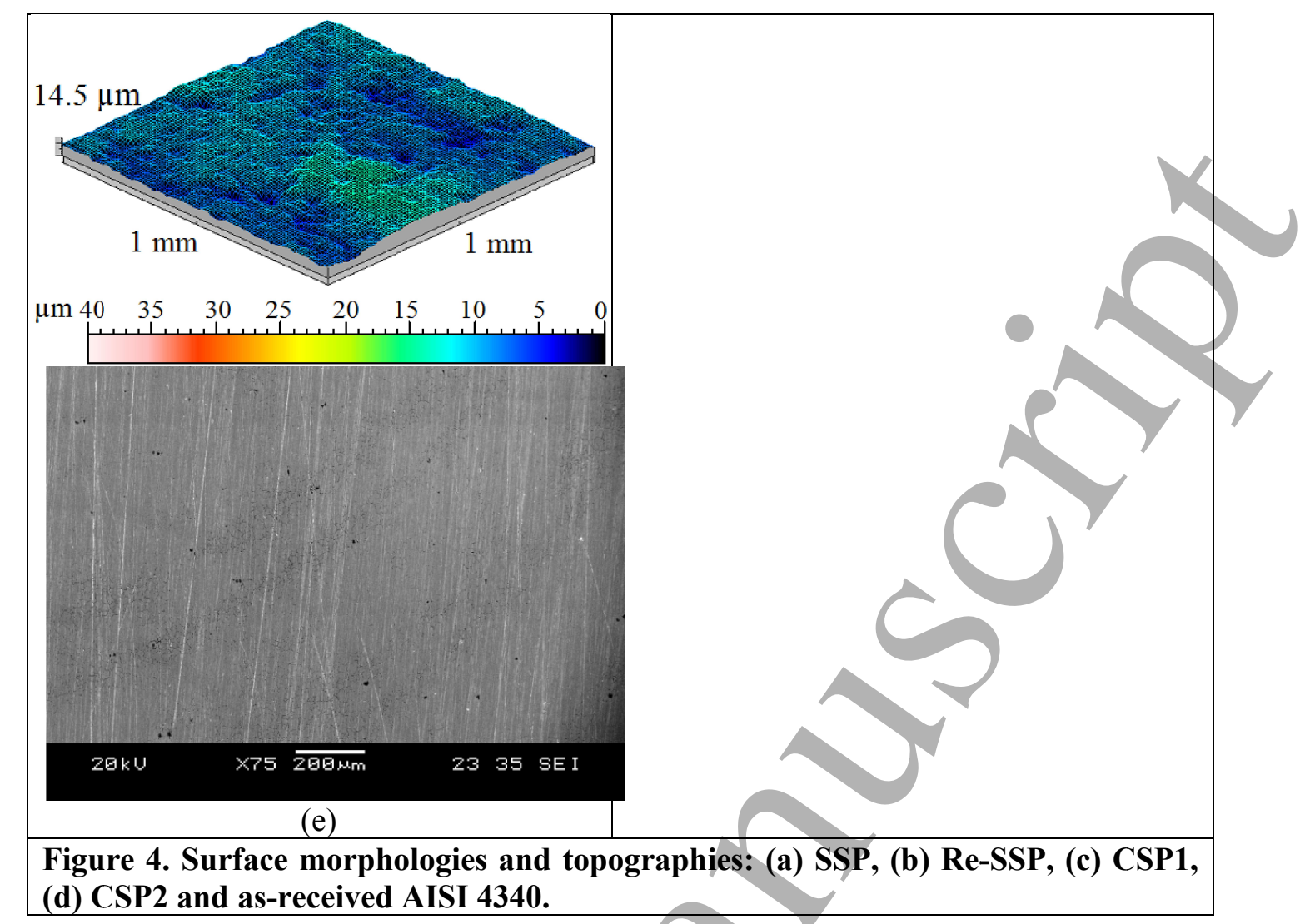

Figure 4. Surface morphologies and
(d) CSP2 and as-received AISI 4340. 


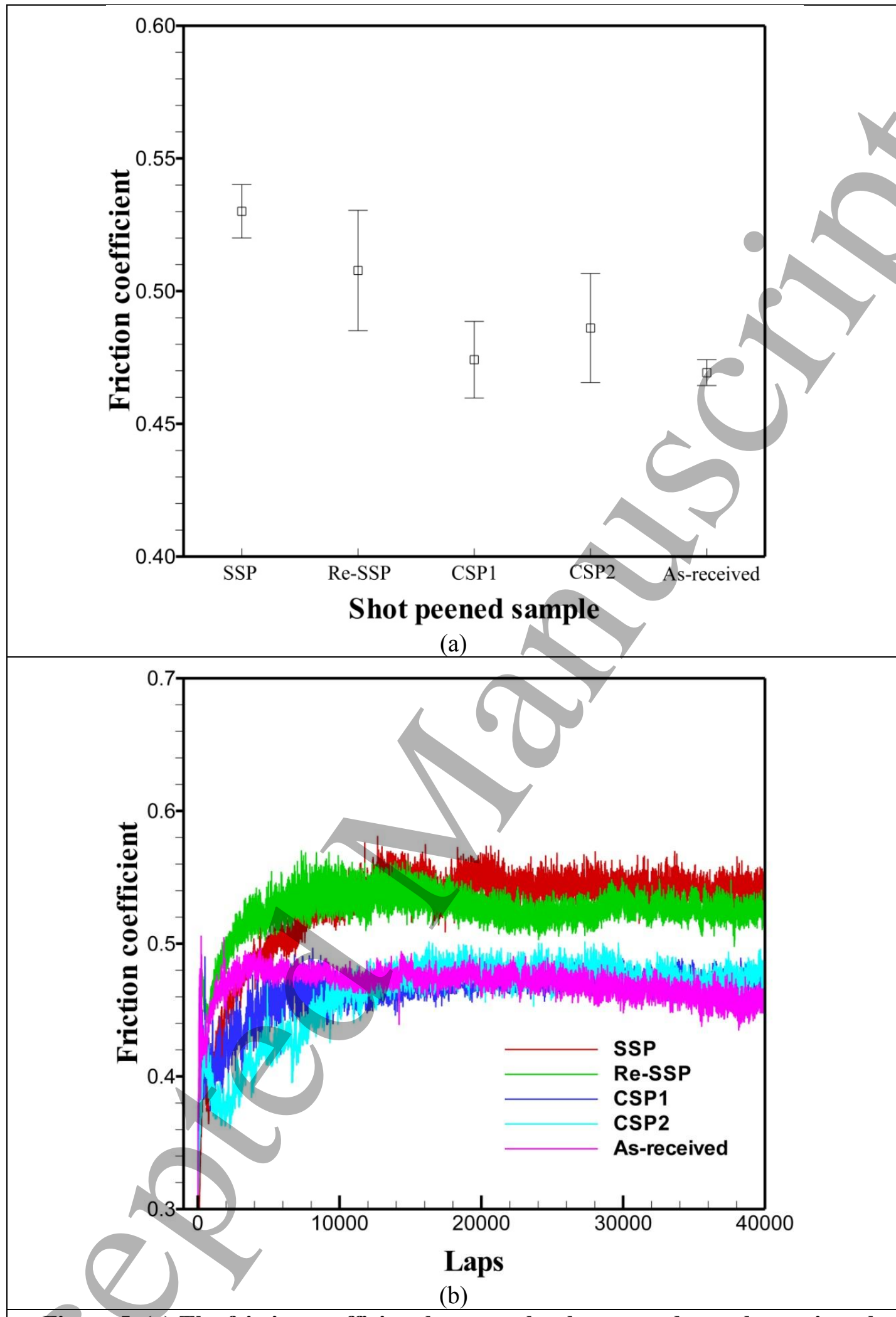

Figure 5. (a) The friction coefficient between the shot peened samples against the $100 \mathrm{Cr} 6$ steel balls in the dry sliding wear tests. (b) The friction coefficients of the shot peened steels against the steel ball under the load of $5 \mathrm{~N}$ as a function of the number of laps. 


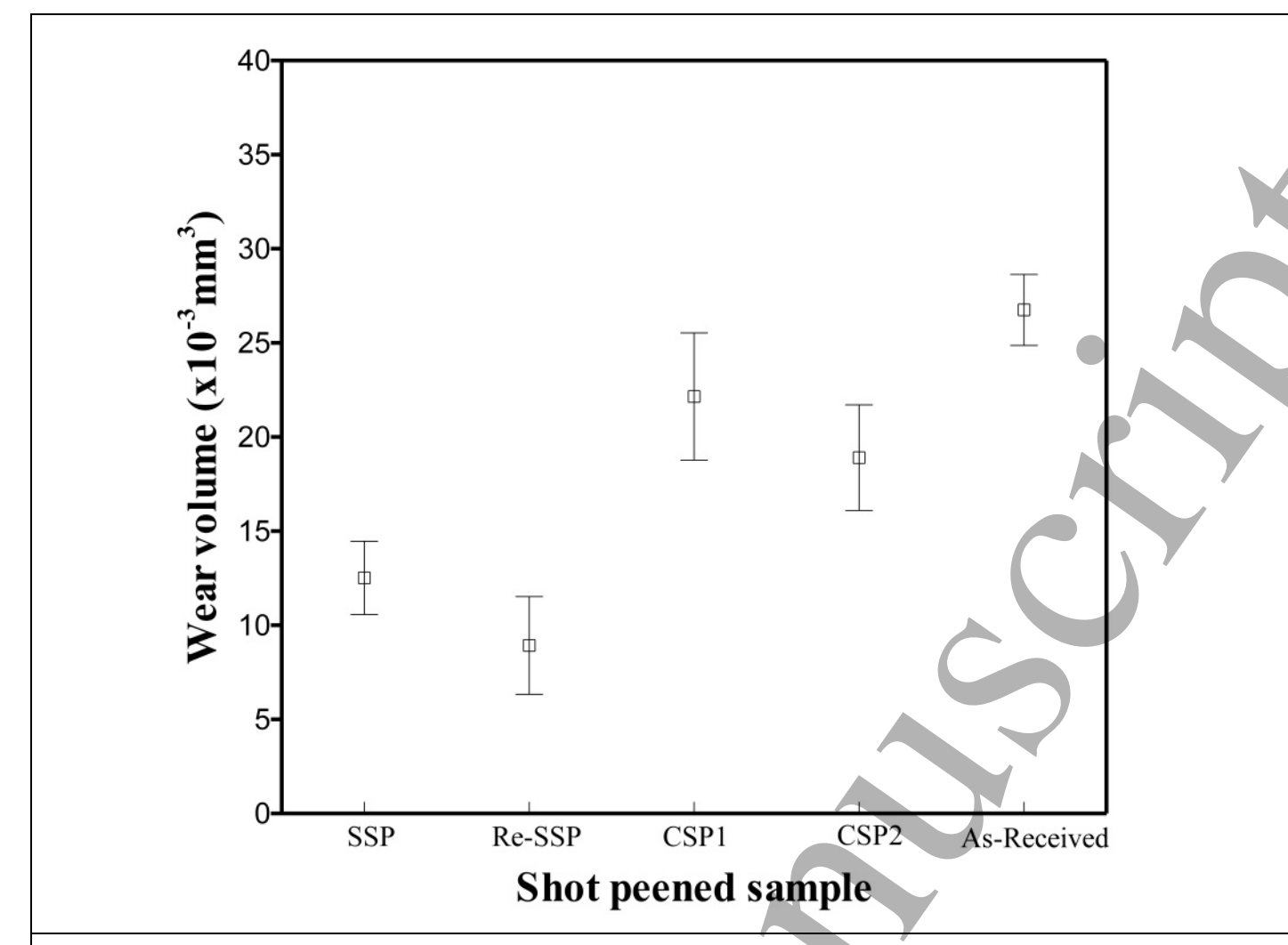

Figure 6. Wear volume of ASIS 4340 at different shot peening conditions. 

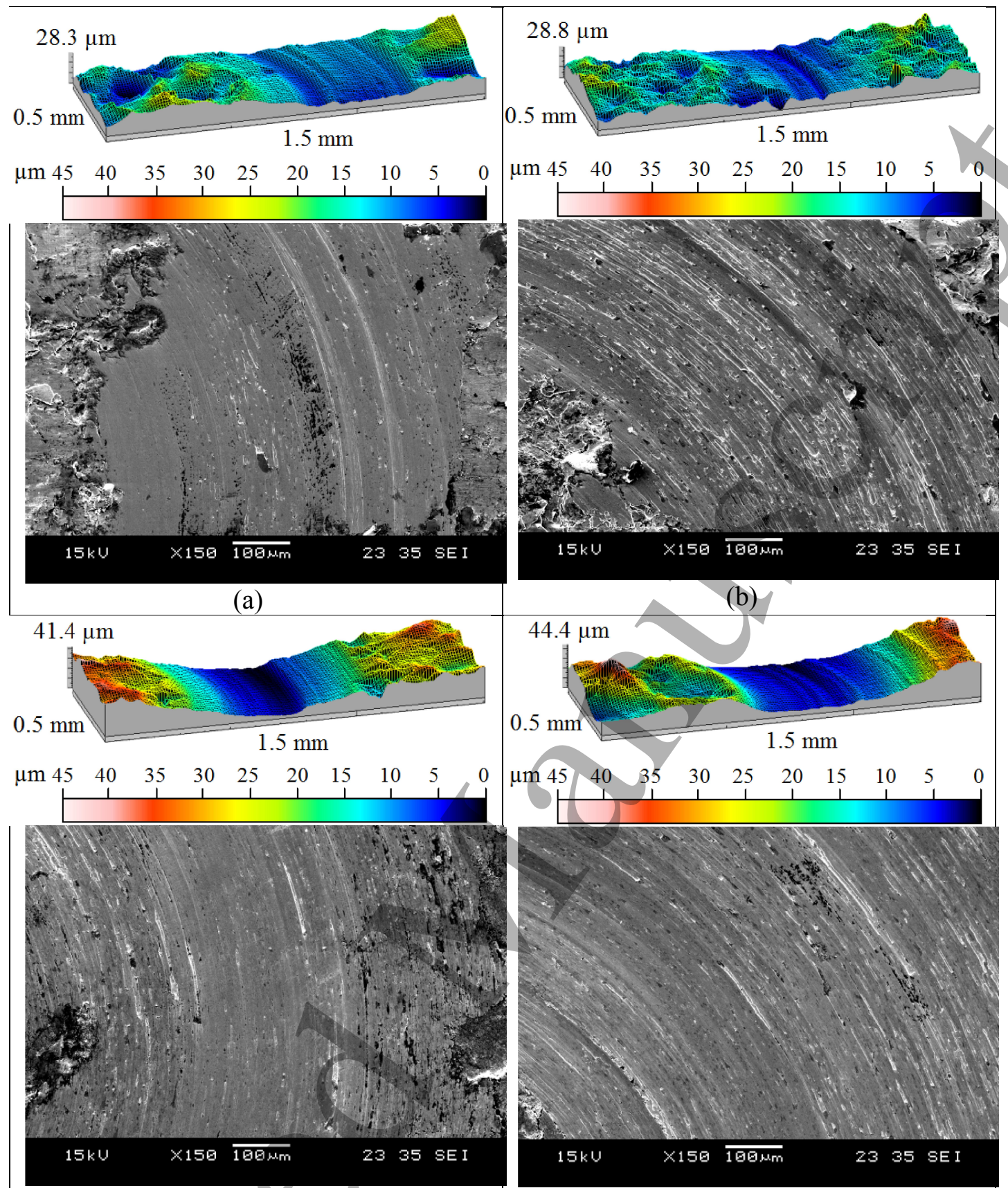

(c)

(d)
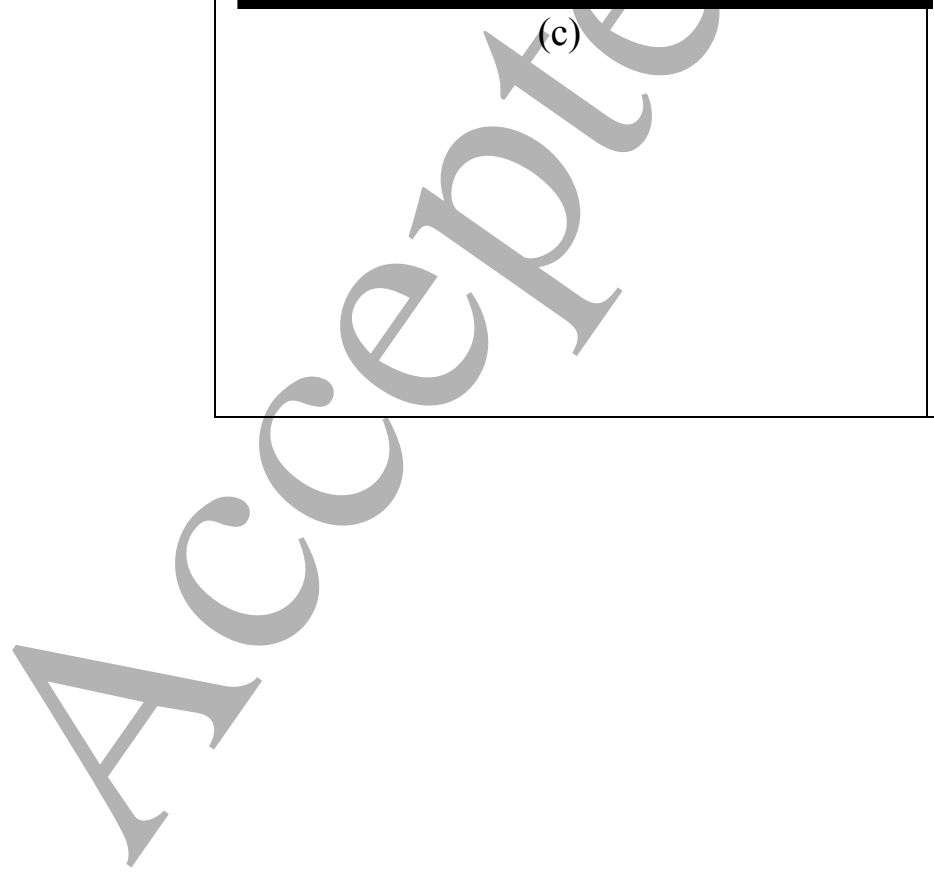


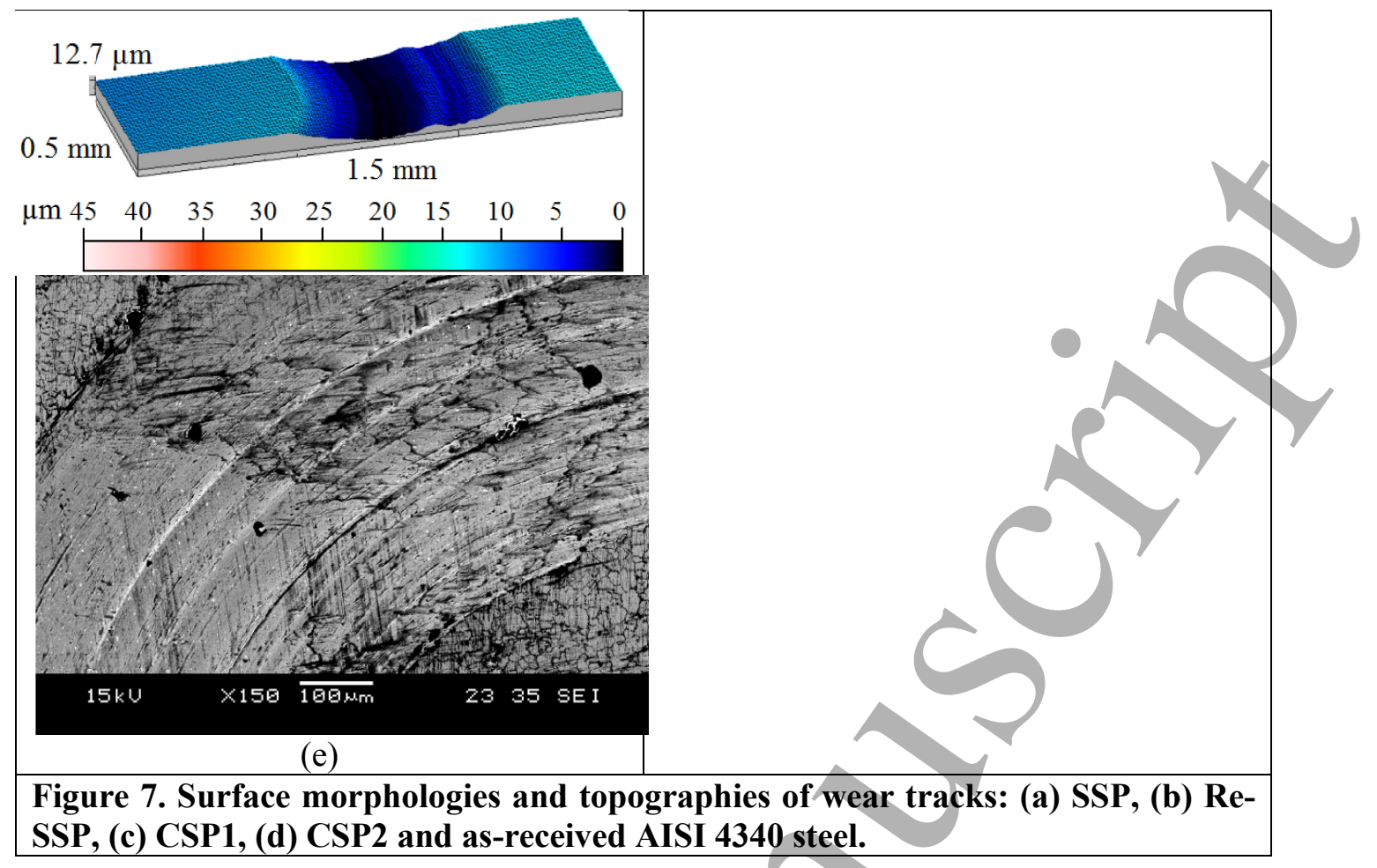

